\title{
GBEP
}

\section{Repetência escolar nos anos iniciais do ensino fundamental: evidências a partir dos dados da Prova Brasil 2009}

Maria Isabel Ramalho Ortigão

Glauco Silva Aguiar

\section{Resumo}

Apresenta os resultados de um estudo exploratório sobre a repetência escolar de alunos dos anos iniciais do ensino fundamental. Usando os dados dos estudantes do $5^{\circ}$ ano avaliados na Prova Brasil 2009, em Matemática, programou-se um modelo de regressão logística (modelo de risco à reprovação) para investigar quais características dos alunos e de suas famílias estão associadas à repetência. Verificou-se no estudo que os meninos são mais propensos à repetição em Matemática do que as meninas e que cursar a pré-escola, fazer os deveres de casa e ter apoio da família nos estudos são importantes fatores associados à diminuição do risco de repetência nesse nível de ensino.

Palavras-chave: repetência; avaliação em Matemática; Prova Brasil. 


\section{Abstract \\ School retention in the elementary school: evidence from the Brazilian Assessment of Educational Progress (Prova Brasil) 2009}

This paper presents the results of an exploratory study on student retention in early elementary school. We investigated the relationship between social background and risk of retention by a logistic regression model (risk of retention model), using data from $5^{\text {th }}$ grade students in the Brazilian Assessment of Educational Progress (Prova Brasil), math section, in 2009. The study found that boys are more likely than girls to repeat math classes. Also, attending pre-school, doing homework and having support from family are facts associated with a decrease in retention levels.

Keywords: retention, assessment in Mathematics, Brazilian Assessment.

\section{Introdução}

A atual fase dos sistemas de avaliação em larga escala, com a introdução de programas de responsabilização, tem aumentado a preocupação com a qualidade das escolas e proporcionado novo fôlego aos debates sobre os fatores a ela associados. Prova disso é a criação do Índice de Desenvolvimento da Educação Básica (Ideb), que conjuga o fluxo escolar, medido por meio das taxas de aprovação, e os resultados dos alunos, pela Prova Brasil. Até a criação do Ideb, esses dois importantes indicadores vinham sendo tratados de forma independente. Com sua instituição, as escolas se veem diante de um novo desafio: ao mesmo tempo que é necessário garantir que os alunos aprendam, é fundamental assegurar também que avancem em sua escolaridade. Para isso, acreditamos ser urgente o investimento em ações voltadas à garantia de aprendizado a todos os alunos, à diminuição das taxas de reprovação, bem como à melhoria das condições de escolarização, entre outras.

Estudos no campo da avaliação da educação têm evidenciado a relação entre características das políticas e das práticas escolares associadas à melhoria do fluxo e do desempenho dos estudantes. Nesse sentido, destacamos a pesquisa realizada com os dados do Sistema de Avaliação da Educação Básica (Saeb) de 2001, com relação aos resultados em Matemática dos alunos do $5^{\circ}$ ano do ensino fundamental (Franco et al., 2007). A partir da implementação de um modelo multinível aos dados, os autores encontraram um conjunto de características que, direta ou indiretamente, influenciam o bom desempenho escolar - entre elas, a ênfase acadêmica da escola, ou seja, o hábito de passar e corrigir dever de casa, o comprometimento do professor com a aprendizagem dos alunos e a abordagem no ensino de Matemática que valorize a resolução de 
problemas, características favoráveis à melhoria da qualidade do ensino.

Em outro estudo realizado com a mesma base de dados do Saeb 2001, Alves, Ortigão e Franco (2007) investigaram características dos alunos associadas à reprovação. Por meio da aplicação de um modelo de regressão logística aos dados dos estudantes do $9^{\circ}$ ano do ensino fundamental que fizeram o teste de Matemática e que à época estavam matriculados em escolas públicas e particulares das capitais brasileiras, o estudo evidenciou que, embora maior capital econômico seja fator de proteção ao risco da reprovação, não protege a todos de maneira similar. "Em especial, alto capital econômico aumenta o risco de reprovação de alunos que se autodeclaram pretos" (p. 178), afirmam os autores. Para eles,

este resultado precisa ser compreendido no contexto da dinâmica das políticas de reprovação e de alocação de alunos em escolas. No Brasil, aprovação e reprovação são, tipicamente, políticas de unidades escolares, decididas de modo relativamente autônomo pelas escolas. Já a alocação dos alunos em escolas é fortemente influenciada pela situação econômica dos alunos, especialmente via a relação entre situação econômica das famílias e local de residência. Famílias negras que possuem melhor situação econômica tendem a ter melhores opções de moradia, o que pode abrir-lhes o acesso a escolas com melhores condições de ensino. No entanto, isto pode colocar seus filhos no grupo de maior risco de reprovação nessas escolas com melhores condições de ensino. Os achados da presente pesquisa são compatíveis com esta dinâmica, sinalizando que o tema da desigualdade racial no Brasil não se reduz a um acontecimento estritamente econômico. (Alves; Ortigão; Franco, 2007, p. 178).

Neste artigo, usamos os dados da Prova Brasil 2009 dos alunos de $5^{\circ}$ ano do ensino fundamental para discutir a reprovação no âmbito da escola pública brasileira. Especificamente, buscamos investigar quais características dos estudantes e de suas famílias se mostram significativas para a diminuição do risco de repetência.

A literatura educacional tem tratado de modo indistinto os pares de conceitos "aprovação" e "promoção", "reprovação" e "repetência", "abandono" e "evasão". No âmbito do Saeb e da Prova Brasil, os conceitos de aprovação, reprovação e abandono se aplicam dentro de um ano letivo, já os de promoção, repetência e evasão, entre anos letivos. Cabe ressaltar que, em nosso estudo, não fizemos distinção entre os conceitos de reprovação e repetência; entendemos repetência como a extensão da fração de alunos matriculados no $5^{\circ}$ ano do ensino fundamental que passaram pela experiência prévia de reprovação porque, por algum motivo, não conseguiram satisfazer aos requisitos formais de avaliação da aprendizagem para serem promovidos ao ano seguinte.

Na sequência deste artigo, apresentamos uma discussão sobre o tema da repetência escolar, trazendo algumas pesquisas que embasaram nosso estudo. Prosseguimos delineando as questões de pesquisa e a abordagem metodológica utilizada para a investigação do risco da reprovação nas escolas públicas brasileiras. Em seguida, discutimos os resultados obtidos 
tanto pela aplicação de técnicas descritivas como pela estimação do modelo de risco utilizado.

\section{Repetência escolar}

Há várias décadas a literatura educacional e as pesquisas empíricas vêm documentando a relação entre desigualdades nos estudos escolares dos alunos e desigualdade de condições das escolas que atendem crianças e jovens de origens sociais distintas. Nesse sentido, destacam-se os estudos de Bourdieu e Passeron (1975), desenvolvidos na França, e a obra de Luiz Antônio Cunha (1975), ambos ocorridos nos anos 1970. O primeiro teve o mérito de chamar a atenção da sociedade para as implicações dos mecanismos escolares de discriminação e de dominação sociocultural nas desigualdades sociais. O segundo destaca-se por evidenciar, a partir da investigação sobre a escolarização das crianças das classes trabalhadoras, o impacto dos mecanismos escolares no acesso e no desempenho escolar diferenciado desse segmento social. Na década seguinte, o interesse pelas questões das desigualdades sociais escolares é renovado pelo contexto político e social da época e pela produção de importantes obras que passam a ressaltar as contradições da educação e a dimensão transformadora da escola (Mello, 1981; Saviani, 1983; Cury, 1983).

Motivada pelos resultados do Saeb, durante a década de 1990 a questão das desigualdades sociais escolares permanece central nos debates educacionais. Embora já seja possível afirmar os avanços conseguidos no acesso à educação básica, principalmente no ensino fundamental, cuja taxa de escolarização bruta das crianças de 6 a 14 anos chega a 97,6\% em 2009 (IBGE. PNAD, 2009), e, consequentemente, na democratização da composição social do público escolar, ainda persistem disparidades entre as condições das escolas frequentadas por alunos de origens sociais diversas, relacionadas a desempenhos escolares diferenciados, reforçando as distinções sociais preexistentes (Brasil. Inep, 2004). Nesse contexto, insere-se o tema da repetência ou reprovação escolar. Apesar de ter caído de 30\% na década de 1990 para os atuais 18,7\%, essa taxa ainda coloca o Brasil na condição de país que mais reprova na educação básica entre os 41 países da América Latina e Caribe, segundo relatório da Organização das Nações Unidas para a Educação, a Ciência e a Cultura (Unesco) sobre a educação mundial publicado em 2010.

Embora já tenha sido considerada uma prática positiva, a repetência é atualmente questionada pelas pesquisas e políticas educacionais, principalmente em função de suas consequências sociais negativas. É reconhecida como um fenômeno social complexo em cuja produção interagem características das escolas e das práticas e políticas escolares, dos alunos e de suas famílias. Mais recentemente, estudos têm mostrado que esse fenômeno também é afetado pela localização espacial da escola (Alves; Lange; Bonamino, 2010). Diversas pesquisas têm procurado evidenciar o quanto a repetência afeta o processo de escolarização e o 
aprendizado dos alunos; ela é ainda a responsável direta pela defasagem idade-série, pela evasão escolar e pelo afastamento do aluno de seus colegas de referência e de seu grupo etário (Leon; Meneses-Filho, 2002).

Maria Helena Patto (1996), por exemplo, com base em ampla revisão da literatura, alerta que as explicações para o fenômeno do chamado 'fracasso escolar', principalmente das crianças pobres, variaram ao longo da história, assumindo diferentes ênfases: deficiências do aluno (de origem médica ou psicológica), fatores intraescolares e carência cultural do estudante e de suas famílias. ${ }^{1}$

No campo da sociologia da educação, estudos voltados à compreensão dos processos de desigualdades educacionais têm focalizado a atenção especialmente para as estratégias educativas familiares. ${ }^{2}$ Nos últimos anos, a família tem sido objeto de estudo privilegiado, não apenas no que se refere aos aspectos econômicos, mas, principalmente, quanto aos esforços para o acesso e distribuição de bens simbólicos e materiais entre seus membros. A existência de um contexto familiar caracterizado por um ambiente de apoio aos estudos permite que os alunos tenham desempenhos escolares melhores.

[...] é na família, com sua configuração determinada, que se conjugam as características de seus componentes, como o sexo e a idade, e se socializam chances diferenciadas de participação na educação, no mercado de trabalho, na qualificação, entre os vários membros familiares. (Bonamino; Franco; Fernandes, 2002, p. 6).

No campo da avaliação educacional, esforços têm sido envidados no sentido de se compreender que características das políticas e práticas educacionais são capazes de explicar os diferentes desempenhos obtidos pelos alunos. Assim, destacamos o estudo realizado por Barbosa e Beltrão (2001), a partir dos dados do Saeb 1999, envolvendo alunos do $5^{\circ}$ ano do ensino fundamental de escolas situadas na Região Sudeste do Brasil. Fazendo uso de uma abordagem multinível aos dados, esses autores investigaram as relações entre os resultados dos estudantes e a adoção de políticas de promoção. Para eles, características como ambiente escolar, tamanho da classe, taxa de reprovação, sistema de promoção e experiência do diretor foram as que se mostraram significativas para explicar a variabilidade dos resultados.

Com propósitos similares, Claudia Fernandes (2003), no âmbito de seu doutoramento, investigou as implicações ocorridas na escola a partir da organização da escolaridade em ciclos. Embora a pesquisa tenha ocorrido em uma perspectiva qualitativa, a autora fez uso dos dados do Saeb 2001 com o intuito de compreender, de modo amplo, algumas relações possíveis de serem estabelecidas entre escolas cicladas e o contexto mais geral do entorno e da comunidade no qual as políticas foram implantadas. Para ela,

[...] os ciclos foram implementados em contextos sociais particularmente difíceis, marcados pela violência. Esse fato concorre para uma maior rotatividade de docentes nas escolas, fazendo com que as escolas organizadas em ciclos não possuam condições escolares ideais e

\footnotetext{
${ }^{1}$ Em artigo recente, Carvalho (2011) discute a atualidade dos estudos de Patto sobre o fracasso escolar, tentando explicar a longevidade e fecundidade de seus achados em um campo tão marcado pela rápida obsolescência de autores, teorias e perspectivas educacionais.

${ }^{2}$ Ver, por exemplo: Romanelli (1994); Alves, Ortigão e Franco (2007); Zuccarelli e Cid (2010), entre outros.
} 
${ }^{3}$ Este trabalho foi apresentado no Seminário sobre Pré-Escola e Qualidade da Educação, organizado pela Fundação Getúlio Vargas (FGV-Rio), em novembro de 2005, no qual muito se discutiu sobre a importância da educação infantil para o desenvolvimento da criança e melhor desempenho escolar. Participaram do Seminário o professor James Heckman, que recebeu o Prêmio Nobel de Economia no ano 2000 , apresentando estudos que comprovam a importância de uma educação pré-escolar de alta qualidade. De acordo com o autor do artigo, referências importantes nessa discussão podem ser encontradas em Heckman e Masterov (2004); Schweinhart (2005); Schweinhart et al. (2005), entre outros. coerentes com os pressupostos de uma concepção pedagógica de ciclos, por exemplo, a estabilidade do corpo docente das escolas. Apesar desse contexto, podemos notar que os professores que atuam em escolas organizadas em ciclos mostram-se mais compromissados e mais responsáveis com o projeto da escola onde atuam e responsabilizam-se mais também pela aprendizagem de seus alunos. (Fernandes, 2003, p. 198).

Em estudo recente, com objetivo de investigar as relações entre a pré-escola e a qualidade da educação, ${ }^{3}$ Rubens Klein (2007), fazendo uso dos dados provenientes das Pesquisas Nacionais por Amostra de Domicílios (PNAD) e dos Censos Escolares, que indicam o crescimento de matrículas na creche e pré-escola, e de análises realizadas com os dados do Saeb 2003, evidenciou uma associação positiva entre o desempenho em Matemática e a entrada na pré-escola ou creche. Para o autor, a análise dos resultados do Saeb 2003 indica que a pré-escola faz diferença e pode atenuar as desigualdades socioeconômicas. No entanto, alerta que a pré-escola atual não é suficiente para igualar o desempenho dos alunos de diferentes níveis socioeconômicos nas escolas públicas (estaduais e municipais) e ainda mais aos das escolas particulares. Para ele,

continua a existir uma associação positiva forte entre nível socioeconômico e desempenho em Matemática para os alunos que entraram na escola pelo maternal ou pela pré-escola ou pela $1^{\mathrm{a}}$ série. Mas, para cada nível socioeconômico, alunos que entraram na escola pelo maternal ou pré-escola têm desempenho melhor que os que entraram somente na $1^{\text {a }}$ série. Mais importante, os alunos que estão no $2^{\circ}$ quintil e que entraram no maternal ou pré-escola têm o mesmo desempenho dos alunos do $5^{\circ}$ quintil que só entraram na $1^{\text {a }}$ série. (Klein, 2007, p. 287).

Tendo como pano de fundo os estudos mencionados acima, usamos os dados da Prova Brasil 2009 para investigar as relações entre características dos estudantes de escolas públicas com a reprovação escolar. A Prova Brasil é uma avaliação censitária de estudantes do $5^{\circ}$ e $9^{\circ}$ anos do ensino fundamental de escolas públicas (estaduais, municipais e federais) que tenham no mínimo 20 alunos matriculados na série avaliada, situadas em área rural e urbana. Essa avaliação ocorre a cada dois anos, quando são aplicados testes cognitivos de Língua Portuguesa e de Matemática, além de questionários contextuais aos alunos participantes e aos professores, diretores, escolas e turmas, e oferece resultados por escola, rede, município, estados e país - os quais também são utilizados no cálculo do Ideb.

Nosso interesse voltou-se, especificamente, à investigação da reprovação no primeiro segmento do ensino fundamental. Queríamos verificar, inicialmente, os níveis de reprovação em um segmento escolar que nos últimos anos adotou, em vários estados e municípios, a organização da escolaridade em ciclos, política que tem sido apontada como uma das responsáveis pelo deslocamento de maiores percentuais de repetência para os anos mais avançados do ensino fundamental. 
As análises preliminares mostraram que a reprovação nessa etapa, a despeito dessas políticas, continua atingindo patamares bastante altos: dados do Censo Escolar indicam que 16,5\% dos estudantes dos anos iniciais do ensino fundamental já passaram pela experiência de reprovação ao menos uma vez em sua vida escolar até aquele momento, confirmando os estudos desenvolvidos pela Unesco e já citados anteriormente.

Apesar de se tratar de percentuais de magnitude considerável, ao analisarmos os dados disponibilizados pelo Instituto Nacional de Estudos e Pesquisas Educacionais Anísio Teixeira (Inep) constatamos uma pequena diminuição nas taxas de reprovação em escolas tanto da rede pública como da particular, bem como nas situadas em zona urbana e rural. A Tabela 1 ilustra nossas primeiras constatações.

\section{Tabela 1 - Taxas de Reprovação nos Anos Iniciais do Ensino Fundamental no Período de 2009 a 2011, de acordo com a Localização da Escola e a Rede Administrativa - Brasil e Regióes}

\begin{tabular}{|c|c|c|c|c|c|c|c|}
\hline & & \multicolumn{6}{|c|}{ Taxas de reprovação no período 2009-2011 } \\
\hline & & \multicolumn{2}{|c|}{2009} & \multicolumn{2}{|c|}{2010} & \multicolumn{2}{|c|}{2011} \\
\hline & & Urbana & Rural & Urbana & Rural & Urbana & Rural \\
\hline \multirow{3}{*}{ Brasil } & Total & 8,0 & 14,5 & 7,3 & 12,2 & 6,5 & 10,5 \\
\hline & Rede Pública & 9,0 & 14,5 & 8,3 & 12,2 & 7,4 & 10,6 \\
\hline & Rede Privada & 2,0 & 8,0 & 2,0 & 7,3 & 2,0 & 5,2 \\
\hline \multicolumn{8}{|c|}{ Regiões geográficas } \\
\hline \multirow{3}{*}{ Norte } & Total & 11,3 & 19,3 & 10,0 & 14,1 & 8,4 & 12,3 \\
\hline & Rede Pública & 12,2 & 19,3 & 10,7 & 14,1 & 9,1 & 12,3 \\
\hline & Rede Privada & 2,1 & 15,3 & 1,9 & 11,4 & 1,8 & 7,2 \\
\hline \multirow{3}{*}{ Nordeste } & Total & 11,2 & 14,8 & 10,2 & 13,1 & 9,2 & 11,3 \\
\hline & Rede Pública & 13,1 & 14,8 & 12,0 & 13,1 & 11,0 & 11,4 \\
\hline & Rede Privada & 2,7 & 8,7 & 2,6 & 8,2 & 2,5 & 5,2 \\
\hline \multirow{3}{*}{ Centro-Oeste } & Total & 7,4 & 9,9 & 7,2 & 9,7 & 6,2 & 8,4 \\
\hline & Rede Pública & 8,4 & 9,9 & 8,3 & 9,7 & 7,2 & 8,4 \\
\hline & Rede Privada & 1,4 & 8,9 & 1,5 & 7,4 & 1,2 & 7,1 \\
\hline \multirow{3}{*}{ Sudeste } & Total & 5,8 & 10,2 & 5,3 & 8,8 & 4,7 & 7,2 \\
\hline & Rede Pública & 6,4 & 10,3 & 6,0 & 8,8 & 5,2 & 7,2 \\
\hline & Rede Privada & 1,8 & 4,4 & 1,8 & 4,2 & 1,9 & 4,0 \\
\hline \multirow{3}{*}{ Sul } & Total & 7,0 & 8,0 & 6,7 & 7,3 & 5,8 & 6,3 \\
\hline & Rede Pública & 7,6 & 8,0 & 7,4 & 7,3 & 6,4 & 6,3 \\
\hline & Rede Privada & 1,6 & 6,1 & 1,5 & 7,8 & 1,5 & 7,8 \\
\hline
\end{tabular}

Fonte: Inep/Edudata, 2012

É possível observar na Tabela 1 que em todas as regiões a reprovação nos anos iniciais do ensino fundamental vem diminuindo no período considerado. No Brasil como um todo, de 2009 a 2011 a taxa de reprovação passou de $8 \%$ para $6,5 \%$ nas escolas urbanas e de $14,5 \%$ para $10 \%$ nas escolas rurais. Observa-se que esse fenômeno é mais frequente nas escolas 
situadas na zona rural do que na urbana. Chama a atenção ainda o fato de a reprovação ser significativamente maior na rede pública do que na particular e não se distribuir homogeneamente entre as regiões brasileiras.

$\mathrm{Na}$ continuidade, enunciamos nossas questões de pesquisa e a abordagem analítica utilizada no estudo. Em seguida, são apresentados e discutidos os principais resultados sobre a distribuição social da repetência escolar na rede pública brasileira, em todas as regiões geográficas. Este estudo envolveu alunos do $5^{\circ}$ ano do ensino fundamental que fizeram o teste de Matemática da Prova Brasil 2009, em razão de certas características de seu processo de escolarização.

\section{Abordagem metodológica}

\section{Questões de pesquisa}

- Que características dos alunos estão associadas ao aumento ou à diminuição do risco de repetência escolar no $5^{\circ}$ ano do ensino fundamental de escolas públicas brasileiras?

- Como essas características estão associadas à probabilidade de ocorrência da repetência escolar dos alunos do $5^{\circ}$ ano do ensino fundamental das escolas públicas brasileiras?

\section{Dados e variáveis utilizados}

Para este estudo, utilizamos os dados da Prova Brasil, aplicada em 2009, com relação aos estudantes do $5^{\circ}$ ano do ensino fundamental que fizeram o teste de Matemática, totalizando informações de 3.112.202 alunos e de 58.374 escolas.

O indicador de repetência foi construído a partir do questionário contextual da Prova Brasil 2009, que pergunta quantas vezes o aluno já repetiu. As respostas foram agrupadas em duas categorias: 'sim', caso o aluno tenha sido reprovado ao menos uma vez ao longo de sua trajetória escolar; e 'não', caso ele nunca tenha sido reprovado. O Quadro 1 apresenta as variáveis utilizadas na modelagem.

Quadro 1 - Variáveis Utilizadas na Modelagem

(continua)

\begin{tabular}{|l|l|l|}
\hline \multicolumn{1}{|c|}{ Variável } & \multicolumn{1}{|c|}{ Codificação } & \multicolumn{1}{c|}{ Descrição } \\
\hline Dependente & $\begin{array}{l}\text { Dicotômica } \\
(1=\text { aluno já repetiu })\end{array}$ & $\begin{array}{l}\text { Obtida a partir da resposta do aluno ao questionário sobre } \\
\text { experiência prévia em reprovação. A variável foi recodificada de } \\
\text { forma a assumir apenas dois valores. }\end{array}$ \\
\hline Repetência & $\begin{array}{l}\text { Dicotômica } \\
(1=\text { menino })\end{array}$ & $\begin{array}{l}\text { Obtida a partir da resposta do aluno ao questionário sobre seu } \\
\text { sexo. }\end{array}$ \\
\hline Gênero &
\end{tabular}




\section{Quadro 1 - Variáveis Utilizadas na Modelagem}

(conclusão)

\begin{tabular}{|c|c|c|}
\hline Variável & Codificação & Descrição \\
\hline Cor declarada & Nominal & $\begin{array}{l}\text { Obtida a partir da resposta do aluno ao questionário sobre sua } \\
\text { cor. A variável foi recodificada de forma a se obter dummies } \\
\text { (preto, pardo, amarelo e índio). }\end{array}$ \\
\hline $\begin{array}{l}\text { Posse de bens } \\
\text { na família }\end{array}$ & Contínua & $\begin{array}{l}\text { Obtida por Análise de Fatores, a partir de itens ordinais do } \\
\text { questionário do aluno em relação a informações sobre evidência } \\
\text { de riqueza e de bens da família. A variável foi particionada em } \\
\text { três percentis e, em seguida, foi dicotomizada. }\end{array}$ \\
\hline $\begin{array}{l}\text { Maior } \\
\text { escolaridade } \\
\text { familiar }\end{array}$ & Ordinal & $\begin{array}{l}\text { Obtida a partir da computação (maior valor) de duas variáveis do } \\
\text { questionário do aluno sobre a escolaridade de sua mãe/madrasta } \\
\text { e seu pai/padrasto. A variável foi recodificada de forma a se obter } \\
\text { dummies. }\end{array}$ \\
\hline $\begin{array}{l}\text { Início da } \\
\text { escolaridade } \\
\text { do aluno }\end{array}$ & Ordinal & $\begin{array}{l}\text { Obtida a partir da resposta do aluno ao questionário sobre } \\
\text { quando ele iniciou sua escolarização. }\end{array}$ \\
\hline $\begin{array}{l}\text { Frequência a } \\
\text { reuniões na } \\
\text { escola }\end{array}$ & Nominal & $\begin{array}{l}\text { Obtida a partir da resposta do aluno ao questionário sobre se } \\
\text { seus pais costumam participar de reuniões na escola. }\end{array}$ \\
\hline $\begin{array}{l}\text { Aluno faz } \\
\text { dever de casa }\end{array}$ & $\begin{array}{l}\text { Dicotômica } \\
(1=\operatorname{sim})\end{array}$ & $\begin{array}{l}\text { Obtida a partir da resposta do aluno ao questionário sobre hábitos } \\
\text { de estudo em relação aos deveres de casa de Matemática. }\end{array}$ \\
\hline $\begin{array}{l}\text { Apoio da } \\
\text { família aos } \\
\text { estudos }\end{array}$ & Contínua & $\begin{array}{l}\text { Obtida por Análise de Fatores, a partir de itens ordinais do } \\
\text { questionário do aluno em relação a informações sobre o quanto } \\
\text { os pais incentivam o aluno a estudar, a fazer as tarefas de casa, } \\
\text { a não faltar à escola, a ler, além de conversar sobre assuntos } \\
\text { relacionados a estudo e à escola. }\end{array}$ \\
\hline $\begin{array}{l}\text { Localização da } \\
\text { escola }\end{array}$ & Nominal & Identifica a localização da escola (urbana ou rural). \\
\hline
\end{tabular}

\section{Abordagem analítica}

A abordagem analítica baseou-se em duas lógicas: descrever e explicar a reprovação. Para isso, iniciamos com as análises descritivas uni e bivariadas, nas quais, simplesmente, computamos o percentual de alunos com experiência prévia em reprovação para as categorias de respostas que expressam características sociodemográficas. Em seguida, implementamos um modelo de regressão logística para a repetência, o qual busca explicar o comportamento de uma variável dependente (Y), no caso a repetência, em função de outras variáveis do aluno (independentes ou explicativas - X). A forma simplificada desse modelo é descrita pela equação:

$$
\operatorname{Pr}(\text { repetência })=\frac{1}{1+\varepsilon^{\left(-\beta_{0}-\beta_{1} X_{1}-\beta_{2} X_{2}-\ldots .-\beta_{p} X_{p}\right)}}
$$

Em que Pr(repetência) é a probabilidade de repetência; $X_{1^{\prime}} X_{2^{\prime}} \ldots . . X_{p}$ são as variáveis explicativas do modelo; e $\beta_{0}, \beta_{1}, \beta_{2}, \ldots . ., \beta_{p}$ são os parâmetros desconhecidos a serem estimados. 
As variáveis independentes consideradas nessa modelagem estão descritas no Quadro 1. Os dados da Prova Brasil não permitem estudar características da escola e do professor devido às limitações do questionário contextual respondido pelo aluno. Uma dessas limitações está relacionada com a medida de repetência, pois a pergunta é se eles repetiram alguma série e quantas vezes, não oferecendo informações sobre a época e as condições em que esta ocorrera.

A escala utilizada, neste estudo, para interpretar os coeficientes na regressão foi obtida pela exponenciação do coeficiente de cada um dos regressores. A exponenciação do coeficiente associado a uma variável representa uma razão (odds ratio - OR) que indica como as chances da repetência se modificam quando se transita entre diferentes categorias de um mesmo fator de risco, sendo a categoria de partida o nível adotado como o de referência. Na regressão logística, calcula-se uma razão (OR) para cada coeficiente da regressão, associado a uma das variáveis independentes (Xj), que indica a chance de repetência quando (Xj) é acrescido de uma unidade $(\mathrm{Xj}+1)$, mantendo-se as outras variáveis constantes.

Em um modelo de risco, quando a variável dependente é igual a 1 (repetência) e a OR da variável independente que está sendo estudada for menor do que 1, esta é considerada um fator de proteção. Já quando a OR de uma variável for maior do que 1, ela é considerada um fator de risco, ou seja, o aumento de uma unidade em (Xj) eleva o risco de ocorrer a repetência. Por exemplo, em nosso modelo, considerando o fator de risco "cor declarada do aluno" e as diferentes categorias desse fator (branco, preto, pardo, amarelo e índio), obtivemos a razão de chance do discente que se autodeclarou preto igual a 1,519. Isso pode ser interpretado como "a chance de um aluno que se autodeclara preto ser reprovado é aproximadamente $52 \%$ maior do que a de um aluno que se autodeclara branco", tomada como categoria de referência para esse fator. Tudo isso controlado pelas outras variáveis incluídas no modelo.

Finalmente, cabe informar que as variáveis abrangidas no estudo foram selecionadas com base em revisão de literatura sobre reprovação e em sua plausibilidade, isto é, na possibilidade de que pudessem estar associadas à repetência.

\section{Resultados}

\section{Estudo exploratório}

Nas escolas públicas brasileiras, observa-se que meninas e meninos apresentam percentuais distintos quanto à reprovação. Em relação às meninas do $5^{\circ}$ ano, cerca de $40 \%$ já repetiram ao menos uma vez, enquanto que, para os meninos, esse percentual atinge quase $60 \%$, como pode ser percebido no Gráfico 1. 


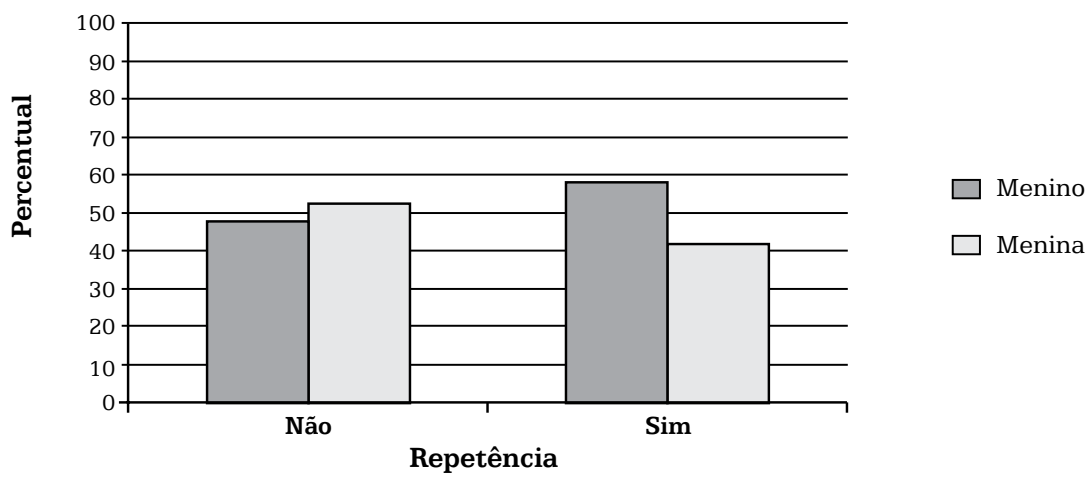

Gráfico 1 - Distribuição Percentual da Reprovação por Gênero Prova Brasil 2009 - Matemática/5 Ano do Ensino Fundamental

Fonte: Microdados Prova Brasil 2009, elaboração dos autores.

Esse resultado se apresenta em consonância com o que tem sido preconizado pela literatura internacional, que tem registrado a tendência de diferenças de gênero. Segundo Madeira e Rodrigues (1998), essa diferença pode estar associada tanto à ampla prevalência nas escolas de ensino fundamental de docentes do sexo feminino quanto à atribuição de significados diversos para homens e mulheres, sobretudo em termos de sociabilidade e de liberdade. O relatório do Programme for International Student Assessment (Pisa) de 2000 (OECD, 2001) realizou amplo estudo para investigar diferenças de gênero nos países avaliados. A pesquisa mostrou que, em 29 países dos 32 analisados, os meninos obtiveram um rendimento maior do que as meninas e o país em que se observou a maior diferença em favor dos meninos foi justamente o Brasil.

O Gráfico 2 informa sobre a distribuição desigual em relação à cor declarada de alunos do $5^{\circ}$ ano de escolas públicas brasileiras com experiência prévia de reprovação. Os estudantes que se autodeclararam pardos apresentam os maiores percentuais de reprovação (quase 50\%) quando comparados com os brancos (cerca de 30\%).

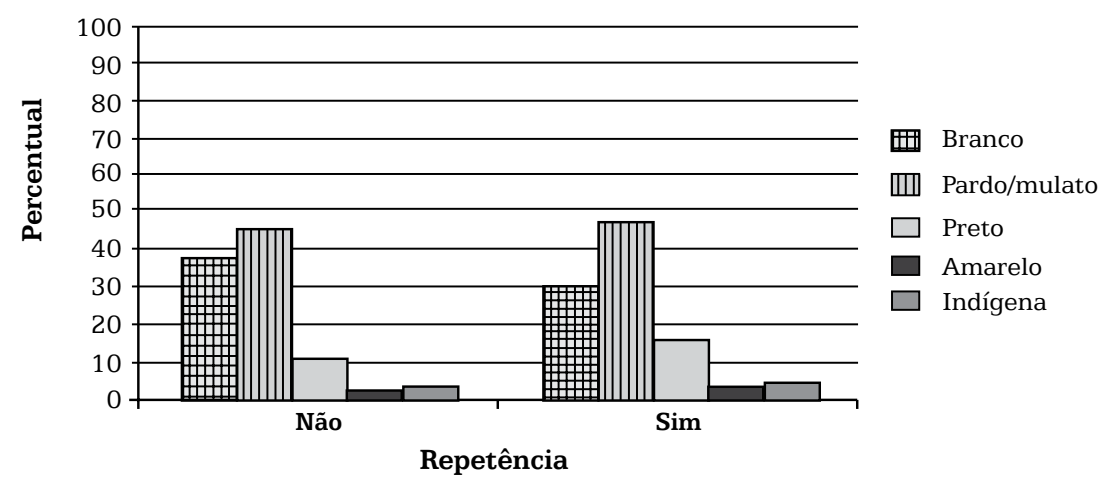

Gráfico 2 - Distribuição Percentual da Reprovação por Cor Declarada Prova Brasil 2009 - Matemática/5 Ano do Ensino Fundamental

Fonte: Microdados Prova Brasil 2009, elaboração dos autores. 
Esse resultado é compatível com outros encontrados na literatura específica, nos quais, sistematicamente, são reportados fatores associados à eficácia escolar. Alguns desses estudos evidenciam a existência de um efeito negativo relacionado à cor declarada nos resultados educacionais (Franco; Mandarino; Ortigão, 2002, Albernaz; Ferreira; Franco, 2002, Barbosa; Beltrão, 2001). Cabe ressaltar que não era nosso interesse discutir questões raciais, no entanto, não podemos deixar de considerar essa característica do aluno quando investigamos a distribuição social dos processos de escolarização vivenciados em nosso País.

Estudos envolvendo questões econômicas e escolarização são recorrentes no Brasil, em especial a partir dos dados das avaliações nacionais. Nossos resultados mostram que os alunos do $5^{\circ}$ ano avaliados em Matemática na Prova Brasil que têm famílias com baixos recursos econômicos apresentam percentuais de reprovação (cerca de 50\%) maiores do que os do grupo que possui nível médio (quase 20\%) ou alto (cerca de 30\%), como pode ser verificados no Gráfico 3.

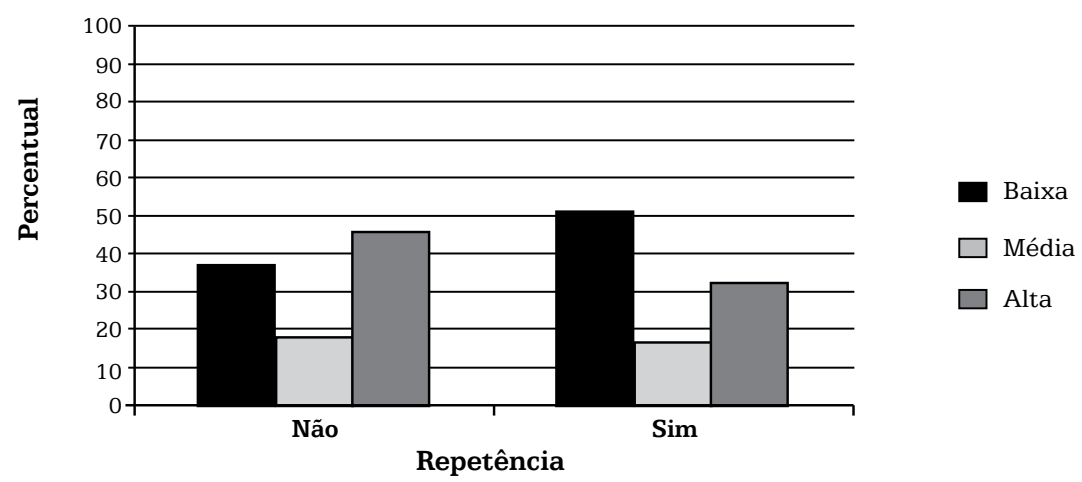

Gráfico 3 - Distribuição Percentual da Reprovação por Posse de Bens - Prova Brasil 2009 - Matemática/5 Ano do Ensino Fundamental

Fonte: Microdados Prova Brasil 2009, elaboração dos autores.

Podemos perceber um aumento significativo quando comparamos os alunos que nunca foram reprovados com os que já foram. Nesse caso, a reprovação atinge mais fortemente os mais pobres, evidenciando uma distribuição desigual da repetência escolar.

A literatura educacional tem destacado a alta correlação entre o nível escolar dos pais e os resultados educacionais de seus filhos. Neste estudo, o indicador de escolaridade familiar é o maior nível de escolaridade do pai ou da mãe. O Gráfico 4 mostra que a reprovação é mais alta entre os estudantes cujos pais possuem baixa escolaridade (aproximadamente 25\%). À medida que esta aumenta, os índices de reprovação dos alunos do $5^{\circ}$ ano do ensino fundamental diminuem. 


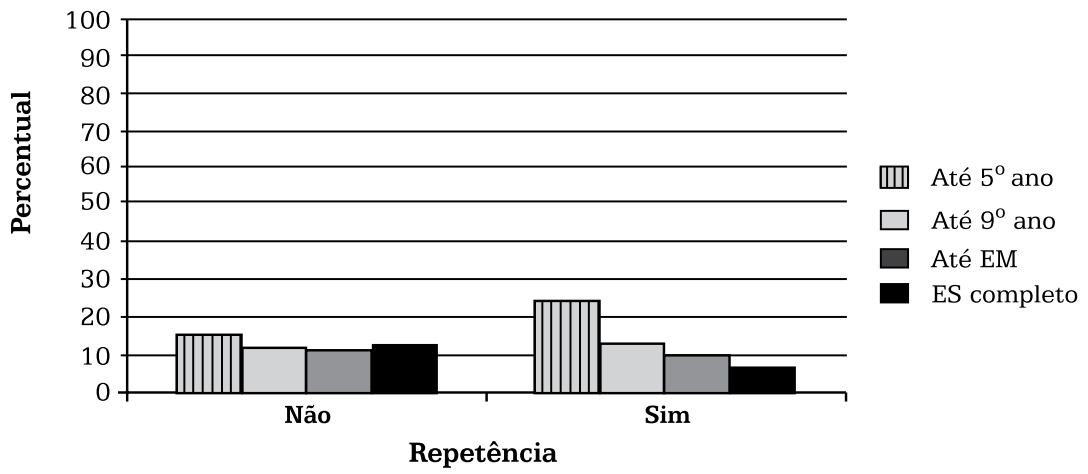

Gráfico 4 - Distribuição Percentual da Reprovação por Nível de Escolaridade Familiar - Prova Brasil 2009 - Matemática/5 Ano do Ensino Fundamental

Fonte: Microdados Prova Brasil 2009, elaboração dos autores.

O Gráfico 5 indica que a reprovação é alta inclusive entre os alunos que ingressaram na pré-escola ou na educação infantil (mais de 60\%). Contudo, se compararmos os que nunca foram reprovados com os que já passaram por essa experiência, pode-se constatar que o fato de os alunos terem entrado mais cedo na escola contribui para diminuir os índices de reprovação. Por outro lado, a entrada tardia na escola é apontada como prejudicial aos estudantes, aumentando as chances de eles serem reprovados.

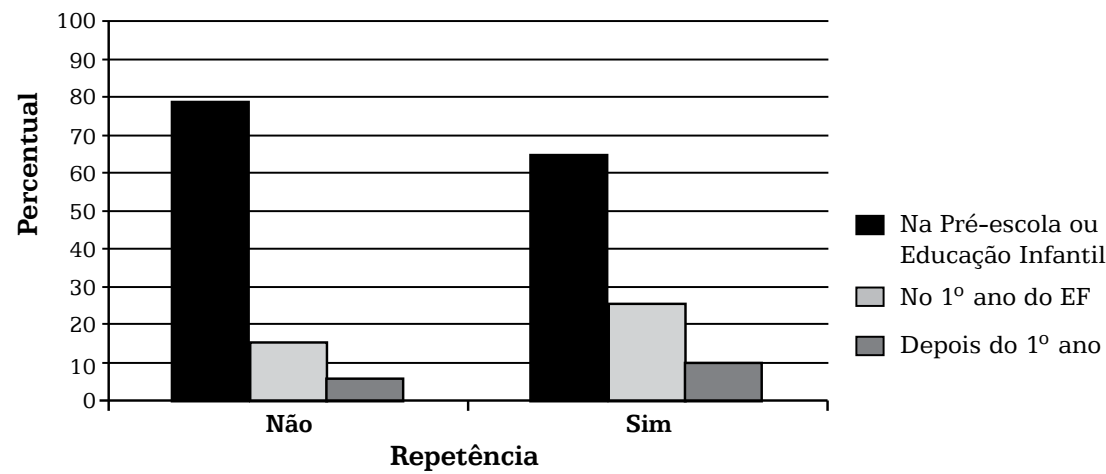

Gráfico 5 - Distribuição Percentual da Reprovação por Início da Escolaridade do Aluno - Prova Brasil 2009 - Matemática/5 Ano do Ensino Fundamental

Fonte: Microdados Prova Brasil 2009, elaboração dos autores.

Como discutido no início deste artigo, a família é um dos ingredientes importantes na melhoria da vida escolar dos alunos. O Gráfico 6 ilustra isso ao evidenciar que a alta frequência da família às reuniões da escola contribui para diminuir a reprovação, ou seja, esta é maior (mais de 50\%) entre os alunos que informam que seus pais raramente vão às reuniões 
em sua escola, quando comparados com os que afirmam que seus pais sempre estão presentes nessas atividades escolares (menos de 50\%).

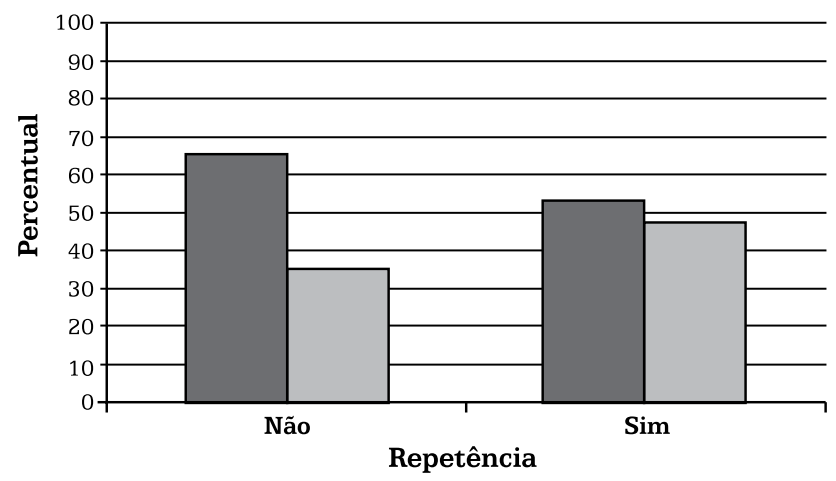

$\square$ Raramente ou nunca

Sempre

Gráfico 6 - Distribuição Percentual da Reprovação por Frequência da Família às Reuniões da Escola - Prova Brasil 2009 - Matemática/5 Ano do Ensino Fundamental

Fonte: Microdados Prova Brasil 2009, elaboração dos autores.

O Gráfico 7 mostra que a reprovação é maior entre os alunos cujas famílias demonstram baixo investimento em apoiar seus filhos nos estudos, correspondendo a 16\% para este grupo, $6 \%$ maior em relação aos discentes que não foram reprovados. Por outro lado, quando comparamos os alunos cujas famílias apresentam alto apoio aos estudos de seus filhos, a reprovação diminui quase $10 \%$.

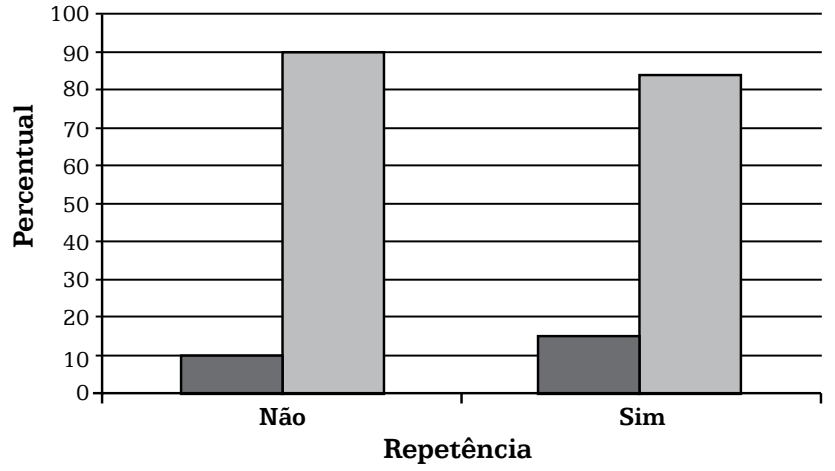

Baixo Alto

Gráfico 7 - Distribuição Percentual da Reprovação de Acordo com Apoio Familiar aos Estudos do Aluno - Prova Brasil 2009 - Matemática/5 Ano do Ensino Fundamental

Fonte: Microdados Prova Brasil 2009, elaboração dos autores.

O cumprimento de tarefas de casa pelo aluno é uma característica recorrente na literatura que discute a qualidade escolar. Corroborando com essa ideia, o Gráfico 8 mostra que a reprovação é maior entre os estudantes que dizem não fazer as tarefas de casa, quando comparados com aqueles que dizem fazê-las. 


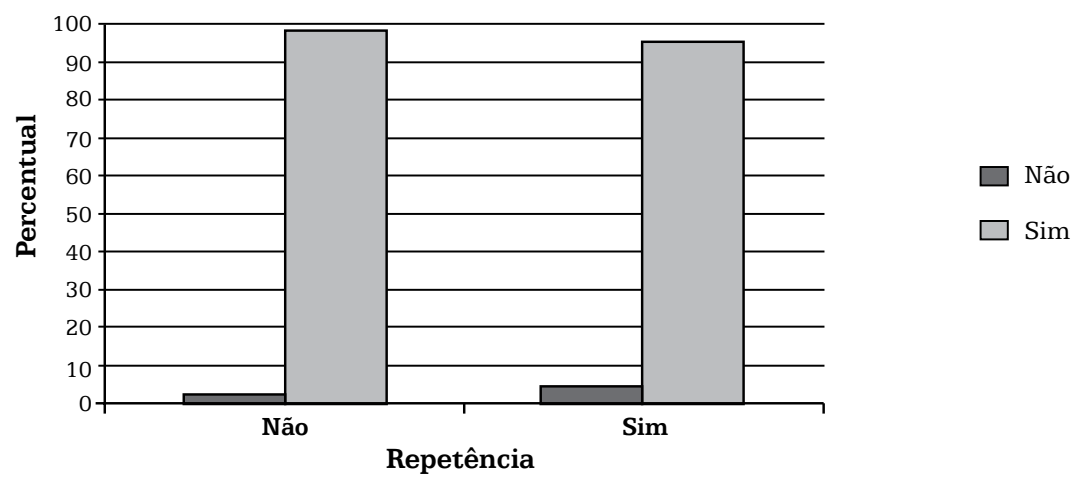

Gráfico 8 - Distribuição Percentual da Reprovação por Cumprimento do Dever de Casa pelo Aluno - Prova Brasil 2009 - Matemática/5 Ano do Ensino Fundamental

Fonte: Microdados Prova Brasil 2009, elaboração dos autores.

Finalmente, o Gráfico 9 indica que a repetência é mais acentuada entre os alunos matriculados em instituições de ensino situadas na zona rural. Esse resultado já era esperado, dadas as características desse tipo de escola e das dificuldades enfrentadas por ela, como observado na pesquisa de Medeiros (2012). Citamos ainda um estudo realizado em escolas urbanas e rurais do Estado de Minas Gerais, em que Soares, Genovez e Galvão (2005) investigaram diferenças de comportamento de itens de avaliação em Geografia aplicados a estes dois grupos de alunos: os de escola urbana e os de escola rural. Para os autores, vários itens se apresentaram mais fáceis aos alunos que estudavam em escola urbana. Este estudo, somado aos achados de Medeiros (2012), pode ser indício de que o currículo da escola rural precisa ser repensado, levando-se em conta as características desses alunos, e não simplesmente fazer uma adaptação do que é proposto para os estudantes de escola urbana.

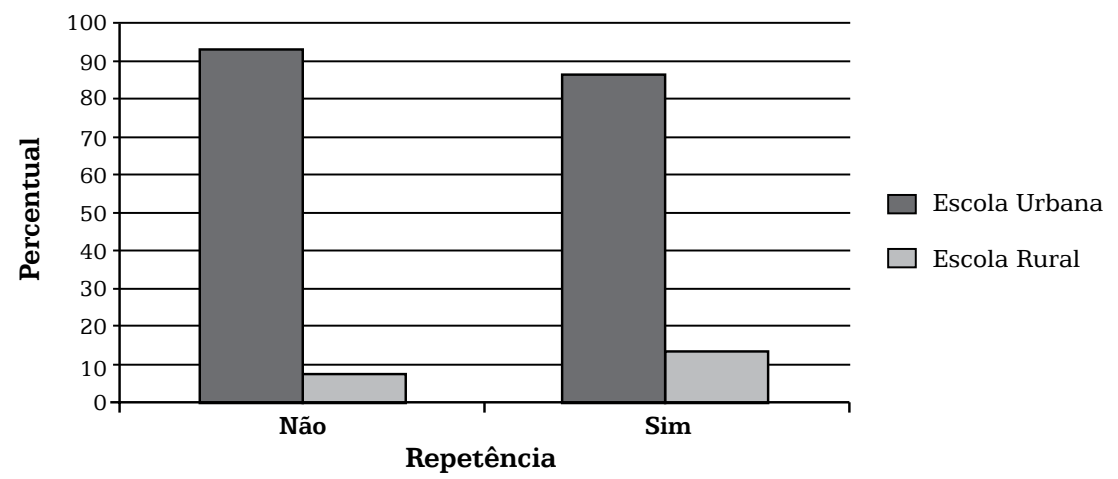

Gráfico 9 - Distribuição Percentual da Reprovação por Localização da Escola Prova Brasil 2009 - Matemática/5º Ano do Ensino Fundamental

Fonte: Microdados Prova Brasil 2009, elaboração dos autores.

Os resultados descritivos apresentados indicam tendências e sugerem variáveis relevantes para a análise do risco da repetência. Contudo, 
alertamos que eles não devem se impor na análise multivariada. Na sequência, apresentamos nossos resultados, obtidos a partir da aplicação do modelo proposto.

\section{Modelo de regressão para a repetência}

Nesta seção, apresentamos os resultados da estimação do modelo de risco de repetência para os alunos do $5^{\circ}$ ano do ensino fundamental das escolas públicas brasileiras. A Tabela 2 apresenta os resultados da estimação do modelo final - são reportados aqui apenas aqueles que se mostraram estatisticamente significativos. Para facilitar a leitura, estão indicadas, na tabela, as categorias de referência consideradas no modelo estimado.

Tabela 2 - Modelo de Risco de Repetência para os Alunos do $5^{\circ}$ Ano do Ensino Fundamental de Escolas Públicas Brasileiras

(continua)

\begin{tabular}{|c|c|}
\hline Variáveis & Razão de Chance (OR) \\
\hline \multicolumn{2}{|l|}{ Gênero } \\
\hline \multicolumn{2}{|l|}{ Menina (referência) } \\
\hline Menino & 1,544 \\
\hline \multicolumn{2}{|l|}{ Cor declarada } \\
\hline \multicolumn{2}{|l|}{ Branco (referência) } \\
\hline Preto & 1,524 \\
\hline Pardo & 1,163 \\
\hline Amarelo & 1,338 \\
\hline Índio & 1,264 \\
\hline \multicolumn{2}{|l|}{ Posse de bens } \\
\hline \multicolumn{2}{|l|}{ Baixo (referência) } \\
\hline Médio & 0,750 \\
\hline Alto & 0,614 \\
\hline \multicolumn{2}{|l|}{ Maior escolaridade familiar } \\
\hline \multicolumn{2}{|l|}{$\begin{array}{l}\text { Pai ou mãe concluiu o ensino } \\
\text { fundamental (referência) }\end{array}$} \\
\hline Pai ou mãe concluiu o ensino médio & 0,602 \\
\hline Pai ou mãe concluiu o ensino superior & 0,617 \\
\hline \multicolumn{2}{|l|}{ Início da escolaridade do estudante } \\
\hline \multicolumn{2}{|l|}{$\begin{array}{l}\text { Aluno entrou no } 1^{\circ} \text { ano do EF } \\
\text { (referência) }\end{array}$} \\
\hline Aluno entrou na pré-escola & 0,614 \\
\hline Aluno entrou após o $1^{\circ}$ ano do EF & 1,142 \\
\hline
\end{tabular}


Tabela 2 - Modelo de Risco de Repetência para os Alunos do $5^{\circ}$ Ano do Ensino Fundamental de Escolas Públicas Brasileiras

(conclusão)

\begin{tabular}{l|l|}
\multicolumn{1}{|c|}{ Variáveis } & Razão de Chance (OR) \\
\hline Pais frequentam reunião escolar & \\
\hline Não (referência) & 0,730 \\
\hline Sim & \\
\hline Apoio familiar aos estudos & 0,917 \\
\hline Abaixo da média (referência) & \\
\hline Acima da média & \\
\hline Aluno costuma fazer dever de casa de Matemática & 0,502 \\
\hline Não (referência) & \\
\hline Frequentemente & 1,572 \\
\hline Localização da escola & $\mathbf{1 , 4 8 0}$ \\
\hline Urbana (referência) & \\
\hline Rural &
\end{tabular}

Observação: Para todos os resultados, p-valor $<0.001$.

Na sequência, apresentamos uma discussão sobre os resultados da Tabela 2, comentando individualmente a interpretação da razão de chance (OR) para cada fator de risco.

\section{Gênero}

$O$ risco de repetência entre os meninos é maior $(\mathrm{OR}=1,544)$ quando comparado com o risco entre as meninas. Isto é, alunos do sexo masculino apresentam chance de repetência 54,4\% maior do que as meninas, levando-se em consideração que esse efeito é controlado pelas outras variáveis incluídas no modelo (ceteris paribus), o que significa dizer que a comparação entre gêneros foi feita livre do impacto das outras varáveis incluídas no modelo, que são mantidas inalteradas.

Diferenças em relação a gênero têm sido apontadas pela literatura educacional. Há, nesse sentido, constatações empíricas de melhorias nos desempenhos das mulheres em relação aos homens (Madeira; Rodrigues, 1998). Esses estudos mostram a escola como um ambiente no qual se atenua a discriminação entre os sexos, o que explicaria o relativo sucesso escolar das meninas nos diferentes níveis socioeconômicos. Essa justificativa, recorrente na literatura brasileira que trata do tema e influenciada pelos estudos franceses de Baudelot e Establet (1991), relaciona-se com uma suposta melhor adaptação das meninas à escola. Por ter uma socialização primária e familiar que favorece um comportamento mais ordeiro e obediente, elas são mais disciplinadas e organizadas que os meninos, e esse tipo de atitude facilita o "ser aluno", o que os 


\footnotetext{
${ }^{4}$ No ano de 2000, o Pisa aplicou testes de Leitura, Matemática e Ciências a uma amostra probabilística de estudantes de 15 anos de 32 países, inclusive o Brasil.

5 Ver, por exemplo: Barbosa e Fernandes (2001); Franco, Mandarino e Ortigão (2001) Albernaz, Ferreira e Franco (2002).
}

franceses definem como "ofício de aluno". De fato, há algumas décadas as estatísticas nacionais vêm mostrando uma diferença considerável entre o desempenho escolar de meninas e meninos. Elas, de alguma forma, têm conseguido articular esse tipo de comportamento com um desempenho escolar mais positivo que os meninos.

Na mesma direção, a investigação internacional desenvolvida no âmbito do Pisa $2000^{4}$ - considerado o mais abrangente estudo sobre gênero e desempenho educacional - observou que, em todos os 32 países que participaram da avaliação, os meninos tiveram rendimento superior ao das meninas em Matemática (OECD, 2001). No Brasil, Andrade, Franco e Carvalho (2003) encontraram resultados análogos utilizando os dados do Saeb 1999, ou seja, a partir do ajuste de modelos multinível controlados por repetência, nível socioeconômico (NSE) e trabalho simultâneo ao estudo, esses autores identificaram que rapazes apresentam desempenho superior ao das moças que estudam nas mesmas escolas. Para os autores, a diferença de desempenho relacionada com gênero varia entre as escolas - naquelas em que o NSE dos alunos é mais alto, a diferença é bastante pequena. Já em escolas onde os discentes têm NSE baixo ocorre o oposto: moças apresentam desempenho superior ao dos rapazes.

\section{Cor declarada}

As razões de chance de repetência dos alunos que se autodeclaram pretos, pardos, amarelos ou índios são maiores do que as dos discentes que se declaram brancos. Observe-se que os alunos que se autodeclaram pretos são os que apresentam maiores riscos de reprovação ( $\mathrm{OR}=1,524)$, seguidos pelos amarelos $(\mathrm{OR}=1,338)$, índios $(\mathrm{OR}=1,264)$ e pardos $(\mathrm{OR}=$ $1,163)$. Verifica-se que a cor declarada do aluno impacta a probabilidade de repetir o ano, indicando ainda a existência de altos índices de desigualdade associada à cor no sistema educacional brasileiro.

A literatura educacional ${ }^{5}$ tem registrado que alunos pretos obtêm resultados expressivamente mais baixos do que os alunos brancos que estudam na mesma escola. Esse resultado é particularmente preocupante, como enfatizado por Albernaz, Ferreira e Franco (2002, p. 22):

O presente resultado sugere que, mesmo dentro da escola e controlando pelo seu nível socioeconômico, o aluno negro tem um pior desempenho de aprendizado. Num contexto onde políticas afirmativas começam a ser debatidas no país, cremos ser necessária uma investigação cuidadosa e detalhada dos aspectos raciais da prática educacional nas escolas brasileiras. Existe alguma forma de discriminação - ainda que sutil e talvez inconsciente - na alocação do aluno negro à sala de aula? Ou por parte do professor em sua atenção individual? Existe algum problema de relevância cultural do currículo ou do material didático que possam torná-los menos interessante ou apropriado para alunos de minorias raciais?

Esse é um tema no qual a convergência de investigações adicionais quantitativas e qualitativas é urgente. 


\section{Posse de bens}

No Brasil, não se deve estudar a realidade educacional sem considerar o nível social ou econômico dos estudantes. Uma crescente literatura nacional baseada principalmente nos dados do Saeb (Franco, 2001, Soares, 2004, Soares; Andrade, 2006, Ortigão; Franco; Carvalho, 2007, entre outros) vem apontando que, no Brasil, o sucesso ou o fracasso do aluno ainda está fortemente ligado à sua origem social e às práticas culturais de sua família, juntamente com a estrutura escolar e as características do próprio aluno - fatores que impactam seu desempenho cognitivo. De fato, nosso modelo mostra que os alunos provenientes de famílias de poder econômico médio e alto apresentam menor risco de reprovação (em ambos os casos OR $<1$ ), quando comparados aos de famílias com baixas condições econômicas. Alunos do $5^{\circ}$ ano do ensino fundamental das escolas públicas provenientes de famílias com maior capacidade econômica têm aproximadamente $40 \%$ a menos de chances de repetir do que seus colegas oriundos de famílias mais pobres. Para alunos provenientes de famílias com média condição econômica, as chances de repetir diminuem um pouco, correspondendo a $25 \%$.

\section{Maior escolaridade familiar}

A chance de repetência dos alunos que afirmam ter pai ou mãe com o ensino médio concluído $(\mathrm{OR}=0,602)$ é menor do que a dos discentes cujos pais concluíram apenas o ensino fundamental; o mesmo acontece com os alunos que afirmam que o pai ou a mãe concluíram o ensino superior ( $\mathrm{OR}=0,617)$. Cabe ressaltar que ter pais tanto com o ensino médio completo quanto com o ensino superior protege contra a repetência, quando comparados com aqueles que concluíram apenas o ensino fundamental - mas quase não há diferença entre eles. Resultados análogos foram observados por Alves, Ortigão e Franco (2007) a partir dos dados dos alunos do $9^{\circ}$ ano na avaliação do Saeb 2001. Para os autores, "a instrução dos pais é um dos fatores que mais se relaciona com o desempenho escolar dos estudantes e, no caso da repetência, quanto maior a instrução, menor é o risco de ocorrência desse fenômeno" (Alves; Ortigão; Franco, 2007, p. 176).

\section{Início da escolaridade do estudante}

Os resultados estimados pelo modelo ratificam a importância das recentes políticas de ampliação da oferta de vagas na educação infantil. A chance de repetência de um aluno que entrou na pré-escola ou educação infantil $(\mathrm{OR}=0,614)$ é quase $40 \%$ menor do que a de um discente que entrou no $1^{\circ}$ ano do ensino fundamental. Por outro lado, entrar na escola após o $1^{\circ}$ ano $(\mathrm{OR}=1,142)$ é fator de risco de repetência e aumenta em $14 \%$ a chance de o aluno repetir o ano escolar. De acordo com o artigo de 
Klein (2007), a entrada do estudante na pré-escola é capaz de minimizar diferenças encontradas nos resultados, em especial, dos alunos cujas famílias têm baixo poder econômico e social.

\section{Pais frequentam reunião escolar}

Alunos que declararam que seus pais frequentam as reuniões da escola têm menores chances de repetir o ano escolar $(\mathrm{OR}=0,730)$ do que aqueles cujos pais não comparecem quando solicitados. Esse resultado sinaliza para a necessidade premente de adoção de estratégias de estreitamento da relação família-escola por parte das escolas públicas, principalmente nesse nível de escolaridade.

\section{Apoio familiar aos estudos}

Conforme esperado, os alunos cujas respostas ao questionário contextual produziram uma medida acima da média para o construto latente que chamamos de "Apoio Familiar aos Estudos" $(\mathrm{OR}=0,917)$ diminuem a sua chance de repetência quando comparados aos seus colegas que não contam com esse tipo de apoio. A escala apoio familiar foi construída a partir de variáveis que perguntavam ao aluno o quanto seus pais o incentivam a não faltar aula, a estudar e fazer o dever de casa, além de se interessarem pelos assuntos escolares de seus filhos. Os resultados encontrados corroboram com outros estudos que investigam a participação dos pais ou responsáveis na vida escolar de seus filhos (Cazelli, 2010, e Barbosa e Sant'Anna, 2010, são exemplos nesse sentido).

\section{Aluno costuma fazer dever de casa de Matemática}

O hábito de fazer lição de casa está associado à diminuição do risco da repetência ( $\mathrm{OR}=0,502)$. Resultado análogo foi obtido em outro estudo realizado no âmbito do Laboratório de Avaliação da Educação (Laed/PUCRio), ${ }^{6}$ em que se verificou que a chance de repetência de um aluno que não faz lição de casa é maior do que a de um discente que não faz porque o professor não passa. Quando a frequência do dever de casa aumenta, diminui a probabilidade da reprovação, sendo esse efeito mais eficaz na Região Sul do Brasil.

\section{Localização da escola}

O simples fato de a escola localizar-se na zona rural $(\mathrm{OR}=1,572)$ é fator de risco para a repetência e aumenta em mais de 50\% a chance de um aluno repetir o ano se comparado a um discente de escola em área
${ }^{6}$ Bonamino, Franco e Fernandes (2002). 
urbana. Estudo recente desenvolvido por Medeiros (2012), a partir de uma amostra de escolas situadas no Rio de Janeiro, evidencia a precariedade de políticas voltadas à educação do campo ou educação rural, em especial em relação à formação de professores. Apoiando-se em Appadurai (2004), Cesar Medeiros (2012) destaca as tensões entre as diferentes visões e representações com as realidades das escolas não urbanas.

\section{Considerações finais}

Este estudo explorou o efeito de características dos alunos e de suas famílias sobre a probabilidade de reprovação no $5^{\circ}$ ano do ensino fundamental de escolas públicas, a partir dos dados da Prova Brasil 2009. A aprovação e a reprovação, no Brasil, são políticas e práticas de unidades escolares, decididas de modo relativamente autônomo por elas. Já a alocação dos alunos em escolas é influenciada pela situação econômica, social e cultural de seus familiares. Estudantes provenientes de famílias com melhor situação econômica tendem a ter melhores opções de moradia, o que pode abrir-lhes o acesso a escolas com melhores condições de ensino. Entre os principais resultados deste estudo, destacam-se:

- A repetência está associada a características de gênero dos alunos: a repetência em Matemática atinge mais os meninos do que as meninas. Os resultados favoráveis aos meninos podem estar relacionados a certos aspectos da cultura escolar, como a valorização de modelos de aprendizagem que implicam comportamentos que prescindem estar sentado para assistir à aula e fazer as tarefas de casa. Tradicionalmente, as meninas apresentam melhor desempenho em Leitura (e/ou Língua Portuguesa); já os meninos se saem melhor em avaliações cujo foco é a Matemática.

- A repetência está associada à cor declarada do aluno: estudantes que se autodeclaram pretos estão mais sujeitos à reprovação do que os alunos brancos ou pardos. Esse resultado aponta para a articulação entre repetência e etnia, denunciando mecanismos de segregação, os quais o sistema educacional ainda não foi capaz de solucionar em nível estrutural.

- A repetência está associada ao apoio escolar que a família oferece ao estudante: alunos pertencentes a famílias que auxiliam em relação ao cumprimento das tarefas escolares, incentivam quanto aos estudos, se interessam pelos assuntos escolares de seus filhos e não permitem que eles faltem às aulas são menos favoráveis à reprovação. Destacamos ainda que uma boa frequência às reuniões da escola também é um fator de proteção à reprovação e há indícios de que, quanto maior a escolaridade de um membro da família, menores são as chances de reprovação do aluno.

- A repetência está associada ao apoio econômico disponibilizado pelas famílias dos alunos: estudantes pertencentes a famílias que 
dispõem de bons recursos econômicos têm menos chances de serem reprovados, quando comparados com alunos cujas famílias dispõem de baixos recursos.

\section{Referências bibliográficas}

ALBERNAZ, A.; FERREIRA, F.; FRANCO, C. Qualidade e equidade no ensino fundamental brasileiro. Pesquisa e Planejamento Econômico, Rio de Janeiro, v. 32, n. 3, 2002.

ALVES, F.; LANGE, W.; BONAMINO, A. A geografia objetiva de oportunidades educacionais na cidade do Rio de Janeiro. In: RIBEIRO, L. C de Q. et al. (Org.). Desigualdades urbanas e desigualdades escolares. Rio de Janeiro: Letra Capital, 2010. p. 67-90.

ALVES, F.; ORTIGÃO, I.; FRANCO. C. Origem social e risco de repetência: interação entre raça-capital econômico. Cadernos de Pesquisa, São Paulo, v. 37, n. 130, p. 161-180, jan./abr. 2007.

ANDRADE, M.; FRANCO, C.; CARVALHO, J. P. de. Gênero e desempenho em matemática ao final do ensino médio: quais as relações? Estudos em Avaliação Educacional, São Paulo, n. 27, p. 7796, jan./jun. 2003.

APPADURAI, A. Dimensões culturais da globalização. Lisboa: Teorema, 2004.

BARBOSA, M. E. et al. Modelagem multinível dos dados do SAEB 1999: relatório técnico. Rio de Janeiro: IBGE, Ence, 2001.

BARBOSA, M. E. F.; BELTRÃO, K. I. Multilevel model applied on Brazilian Educational System Assessment. 2001. Disponível em: < http://isi.cbs.nl/iamamember/CD2/pdf/521.PDF>. Acesso em: 22 ago. 2012.

BARBOSA, M. E. F.; FERNANDES, C. A escola brasileira faz diferença? Uma investigação dos efeitos da escola na proficiência em Matemática dos alunos da $4^{\mathrm{a}}$ série. In: FRANCO, Creso (Org.). Promoção, ciclos e avaliação educacional. Porto Alegre: ArtMed, , 2001. p. 155-172.

BARBOSA, M. L. O.; SANT'ANNA, M. J. G. As classes populares e a valorização da educação no Brasil: a geografia objetiva de oportunidades educacionais na cidade do Rio de Janeiro. In: RIBEIRO, L. C. et al (Org.). Desigualdades urbanas e desigualdades escolares. Rio de Janeiro: Letra Capital, 2010. p. 155-174. 
BAUDELOT, C.; ESTABLET, R. Allez les filles. Paris: PUF, 1991.

BONAMINO, A.; FRANCO, C.; FERNANDES, C. Repetência escolar e apoio social familiar: um estudo a partir dos dados do SAEB 2001 relatório técnico. Rio de Janeiro: PUC-Rio, Laed, 2002.

BOURDIEU, P.; PASSERON, J. C. A reprodução: elementos para uma teoria do sistema de ensino. Rio de Janeiro: Francisco Alves, 1975.

BRASIL. Instituto Nacional de Estudos e Pesquisas Educacionais Anísio Teixeira (Inep). Qualidade da educação: uma nova leitura do desempenho dos estudantes de $8^{\mathrm{a}}$ série do ensino fundamental. Brasília, 2004.

CAMPBELL, F. A. et al. Early childhood education: young adult outcomes from the Abecedarian project. Applied Developmental Science, v. 6, n. 1, p. 42-57, 2002.

CARVALHO, José Sérgio F. de. A produção do fracasso escolar: a trajetória de um clássico. Psicologia USP [online], São Paulo, v. 22, n. 3, p. 569-578, set. 2011. Disponível em: <http://www.scielo.br/pdf/pusp/ v22n3/aop2411.pdf>. Acesso em: 22 ago. 2012.

CAZELLI, S. Jovens, escolas e museus: os efeitos dos diferentes capitais - a geografia objetiva de oportunidades educacionais na cidade do Rio de Janeiro. In: RIBEIRO, L. C. de Q. et al (Org.). Desigualdades urbanas e desigualdades escolares. Rio de Janeiro: Letra Capital, 2010. p. 175216.

CUNHA, Luiz A. Educação, Estado e democracia no Brasil. Rio de Janeiro: Cortez, 1975.

CURY, Carlos Roberto. Educação e contradição: elementos metodológicos para uma teoria crítica do fenômeno educativo. São Paulo: Cortez, Autores Associados, 1983.

FERNANDES, C. O. A construção do currículo na escola pública: a interação de propostas curriculares oficiais com o projeto educativo de uma unidade escolar. 1997. Dissertação (Mestrado em Educação) Pontifícia Universidade Católica do Rio de Janeiro, 1997.

FERNANDES, C. O. A escolaridade em ciclos: práticas que conformam a escola dentro de uma nova lógica - a transição para a escola do século XXI. 2003. 353 f. Tese (Doutorado em Educação) - Pontifícia Universidade Católica do Rio de Janeiro, 2003. Disponível em: < http:// www.unirio.br/cch/neephi/textos/TESE\%20DOUTORADO_CLAUDIA\%20 FERNANDES.pdf>. Acesso em: 10 jul. 2012. 
FORQUIN, J. C. As abordagens sociológicas do currículo: orientações teóricas e perspectivas de pesquisa. Educação e Realidade, Porto Alegre, v. 21, n. 1, p.187-198, 1995.

FRANCO, C.; ALBERNAZ, A.; ORTIGÃO, I. Características escolares que melhoram o desempenho dos alunos da $8^{a}$ série do ensino fundamental: evidências a partir dos dados do SAEB 2001 - relatório técnico. Rio de Janeiro: PUC-Rio, 2004.

FRANCO, C. et al. Eficácia escolar en Brasil: investigando prácticas y políticas escolares moderadoras de desigualdades educacionales. In: CUETO, S. (Org.) Educación y brechas de equidad en América Latina. Santiago: Fondo de Investigaciones Educativas / PREAL, 2007. Tomo I, p. 223-249.

FRANCO, C.; MANDARINO, M.; ORTIGÃO, M. I. Projeto pedagógico de escola promove eficácia e equidade em educação? Revista Undime, Rio de Janeiro, v. 7, n. 2, p. 30-46, 2002.

FUNDAÇÃO CESGRANRIO. Relatório técnico do SAEB: fatores associados ao desempenho em língua portuguesa e matemática - a evidência do SAEB 2003. Rio de Janeiro: Fundação Cesgranrio. 2004

HECKMAN, J. J.; MASTEROV, D. V. The productivity argument for investing in young children. Chicago: Committee on Economic Development, 2004. Disponível em: < http://jenni.uchicago.edu/ human-inequality/papers/Heckman_final_all_wp_2007-03-22c_jsb. pdf>. Acesso em: 12 fev. 2007.

INSTITUTO BRASILEIRO DE GEOGRAFIA E ESTATÍSTICA (IBGE). Pesquisa nacional por amostra de domicílios: síntese de indicadores. 2009. Disponível em: < http://www.ibge.gov.br/home/estatistica/ populacao/trabalhoerendimento/pnad2009/pnad_sintese_2009.pdf > . Acesso em: 20 nov. 2012.

KLEIN, R. A pré-escola no Brasil. Revista Electrónica Iberoamericana sobre Calidad, Eficacia y Cambio en Educación, v. 5, n. 2, 2007. Disponível em: < http://www.rinace.net/arts/vol5num2e/art19.pdf>. Acesso em: 22 ago. 2012.

LEON, F. L. L. de; MENEZES-FILHO, N. A. Reprovação, avanço e evasão escolar no Brasil. Pesquisa e Planejamento Econômico, Rio de Janeiro, v. 32, n. 3, p. 417-451, 2002.

MADEIRA, F.; RODRIGUES, E. M. Recado dos jovens: mais qualificação. In: COMISSÃO NACIONAL DE POPULAÇÃO E DESENVOLVIMENTO. 
Jovens acontecendo na trilha das políticas públicas. Brasília: CPND, 1998. v. 2, p. 427-498.

MEDEIROS, C. M. Escolas rurais de Teresópolis: um estudo sobre o fenômeno da urbanização do campo e das práticas pedagógicas. 2012. Dissertação (Mestrado em Educação) - Faculdade de Educação da Baixada Fluminense, Universidade do Estado do Rio de Janeiro, 2012.

MELLO, G. N. de. Magistério de $1^{\circ}$ grau: da competência técnica ao compromisso político. São Paulo: Cortez, Autores Associados, 1981.

NOGUEIRA, C. M. M.; NOGUEIRA, M. A. A sociologia da educação de Pierre Bourdieu: limites e contribuições. Educação \& Sociedade, v. 23, n. 78, p.15-36, abr. 2002 .

\section{ORGANIZATION FOR ECONOMIC CO-OPERATION AND}

DEVELOPMENT (OECD). Knowledge and skills for life: first results from OECD Programm for International Student Assessment (PISA) 2000. Paris, 2001. Disponível em: <http://www.oecd.org/edu/school/ programmeforinternationalstudentassessmentpisa/33691596.pdf $>$. Acesso em: jul. 2004.

ORTIGÃO, M. I. R.; FRANCO, C.; CARVALHO, J. B. P. A distribuição social do currículo de matemática: quem tem acesso a tratamento da informação? Educação Matemática Pesquisa, São Paulo, v. 9, n. 2, p. 249-273, 2007.

PATTO, M. H. A produção do fracasso escolar: histórias de submissão e rebeldia. 2. ed. São Paulo: Casa do Psicólogo, 1996.

ROMANELLI, G. O significado da escolarização superior para duas gerações de famílias de camadas médias. In: VEIGA-NETO, A. J. (Org.). Sociologia da educação. Porto Alegre: Anped, 1994. p.43-64.

SAVIANI, D. Escola e democracia. São Paulo: Autores Associados, 1983.

SCHWEINHART, L. J. The High/Scope Perry Preschool study through age 40: summary, conclusions and frequently asked questions. 2005. Disponível em: < http://www.highscope.org/file/Research/ PerryProject/3_specialsummary\%20col\%2006\%2007.pdf>.

SCHWEINHART, L. J. et al. Lifetime effects: the high/scope Perry Preschool study through age 40. Ypsilanti, MI: High/Scope Press, 2005.

SOARES, J. F. Qualidade e equidade na educação brasileira: fatos e possibilidades. In: BOCK, C.; SCHWARTMAN, S. Os desafios da educação no Brasil. Rio de Janeiro: Nova Fronteira. 2005. p. 91-117. 
SOARES, J. F.; ANDRADE, R. J. Nível socioeconômico, qualidade e equidade das escolas de Belo Horizonte. Ensaio: Avaliação e Políticas Públicas em Educação, Rio de Janeiro, v. 14, n. 50, p. 107-126, 2006.

SOARES, T. M.; GENOVEZ, S. F. M.; GALVÃO, A. F. Análise do comportamento diferencial dos itens de geografia: estudo da $4^{a}$ série avaliada no Proeb/Simave, 2001. Estudos em Avaliação Educacional, São Paulo, v. 16, n. 32, p. 81-110, jul./dez. 2005.

UNESCO. Llegar a los marginados: informe de seguimiento de la EPT [Educación para Todos] en el mundo. 2010. Disponível em: <http:// unesdoc.unesco.org/images/0018/001865/186525S.pdf>. Acesso em: 10 ago. 2012.

ZUCCARELLI, C.; CID, G. Oportunidades escolares e escolhas familiares no Rio de Janeiro. In: RIBEIRO, L. C. de Q. et al.(Org.). Desigualdades urbanas e desigualdades escolares. Rio de Janeiro: Letra Capital, 2010. p. 249-276.

Maria Isabel Ramalho Ortigão, doutora em Educação pela Pontifícia Universidade Católica do Rio de Janeiro (PUC-Rio), é professora da Faculdade de Educação da Baixada Fluminense da Universidade do Estado do Rio de Janeiro (UERJ) e do Programa de Pós-Graduação em Educação, Culturas e Comunicação em Periferias Urbanas (Mestrado Acadêmico) atual coordenadora do Programa, Rio de Janeiro, Rio de Janeiro, Brasil. isabelortigao@terra.com.br

Glauco Silva Aguiar, doutor em Educação pela Pontifícia Universidade Católica do Rio de Janeiro (PUC-Rio), é professor pesquisador do Projeto Observatório das Periferias Urbanas e professor da Educação Básica na área de Matemática e Estatística. Está vinculado ao Sistema Colégio Militar do Brasil e Fundação Osório, Rio de Janeiro, Rio de Janeiro, Brasil.

glaucoaguiar@uol.com.br

Recebido em 31 de agosto de 2012.

Aprovado em $1^{\circ}$ de março de 2013. 